DOI: $10.15290 /$ bsl.2016.08.02

\title{
Maciej Dajnowski
}

Wydział Filologiczny

Uniwerstet Gdański

e-mail: mdajnowski@wp.pl

\section{Mapy literackie - kłącze, fałdy \\ $\mathrm{i}$, „efekt przedpokoju”}

1. Mapa $\mathrm{w}$ potocznym rozumieniu ma charakter reprezentacji par excellence. Z perspektywy humanistyki po Nietzschem i Heideggerze, ufundowanej na krytyce filozofii przedstawienia, musi być jednak opisywana w innych kategoriach. Interesujących możliwości w tym wymiarze dostarcza Deleuze'jańska koncepcja kłączowatości/rizomatyczności tekstu kultury, która znosi dychotomie znaczące/znaczone, reprezentujące/reprezentowane etc. ${ }^{1}$ Mapa rozumiana zgodnie $\mathrm{z}$ modelem kłącza wchodzi w wielopiętrowe i wielokierunkowe relacje z rzeczywistością, odbiorcą, kodami kulturowymi, które "czytelnik" wnosi do niej w procesie interpretacji, z innymi tekstami, z którymi może być zestawiana, porównywana etc. Mapą jest w świetle tego rodzaju refleksji nie fizycznie utrwalona "odbitka”, odwzorowanie, deskrypcja fragmentu rzeczywistości, ale efekt interpretacyjnych zmagań, których ta pierwsza jest jedynie polem².

1 Por. np. G. Deleuze, F. Guattari, Kłacze, przeł. B. Banasiak, „Colloquia Communia” 1988, nr 1-3; por. też: B. Banasiak, Nomadologia Gillesa Deleuze'a, „Hybris” 2001, nr 1, czasopismo elektroniczne: http://magazynhybris.com/index.php/archiwum/11-archiwum/34-hybris-01 [dostęp 12.10.2015].

${ }^{2}$ W zbliżony sposób fenomen mapy analizują przedstawiciele anglosaskiej kartografii krytycznej; por. np. J.W. Crampton, J. Krygier, An Introduction to Critical Cartography, "ACME. An International E-Journal for Critical Geographies" 2005, vol. 4, nr 1: http://acme-journal.org/ index.php/acme/article/view/723/585 [dostęp 12.10.2015]; J.B. Harley, Maps, knowledge, and power, w: The Iconography of landscape. Essays on the symbolic representation, design and use of past 
2. Tak rozumiana mapa - wyinterpretowany sens pewnego wycinka świata - może zostać określona także jako fałd/fałda ${ }^{3}$, pod tym terminem ukrywa się domniemanie całkowitej zależności pozornie wewnętrznego sensu owego światoobrazu/przedstawienia od zewnętrznej względem kartograficznego artefaktu pracy interpretacyjnej („wnętrze jest fałdem zewnętrznego" $\left.{ }^{4}\right)$.

3. Geopoetyczna/imagologiczna mapa Polski (Mitteleuropy, świata) jest więc "pofałdowana” czy "plisowana” w tym sensie, że wyróżnione na niej (nacechowane symbolicznie silniej niż inne) obszary mają charakter metaforycznych fałd - utrwalonych w literaturze/kulturze tekstów/dyskursów/interpretacji stabilizujących pewien (roszczący sobie pretensje do obiektywizmu przedstawienia) obraz w świadomości/wyobraźni zbiorowej. Są owe fałdy wyrazem oddziaływania w różnym stopniu uświadamianych porządków ideologicznych/symbolicznych składających się na naszą zbiorową świadomość/tożsamość. Mają więc charakter (1) historyczny, (2) terytorialno-kulturowy, (3) środowiskowo-kulturowy etc.

4. Powstawanie tego rodzaju fałd - ognisk znaczeń symbolicznych wiąże się dialektycznie z kształtowaniem „kontrafałd”, to jest obszarów słabiej zaznaczonych na wyobrażonej mapie kraju (Europy, świata, etc.). Jeżeli silne symbolicznym dyskursem są w kulturze polskiej Kraków, Podhale, Kaszuby, Kresy, zbiór „kontrafałd” reprezentują słabsze (w sensie symbolicznej reprezentacji) jednostki terytorialno-kulturowe - Giecz, Podkarpacie, Kociewie, Krajna, Pałuki, Sejneńszczyzna.

Amplituda nasycenia poszczególnych obszarów przestrzeni geograficznej znaczeniami symbolicznymi (,rzutowana z osi wyboru na oś kombinacji", jeżeli wolno sobie pozwolić na żart w tej mierze) odpowiada różnicom między centralnym a peryferyjnym położeniem ich na imagologicznej mapie, przy czym, jeśli posłużyć się Łotmanowskim przeciwstawieniem centrum semiosfery i jej peryferii ${ }^{5}$, kontaminowanym z dychotomią "miejsca”

environments, ed. by D. Cosgrove, S. Daniels, Cambridge 1988; D. Wood, The Fine Line Between Mapping and Mapmaking, "Cartographica" 1993, vol. 30, nr 4 oraz D. Wood, J. Fels, The Nature of Maps: Cartographic Constructions of the Natural World, "Cartographica” 2008, vol. 43, nr 3.

3 G. Deleuze, Le pli: Leibnitz et le baroque, Paris 1988; mimo sterminologizowania w polskiej refleksji Deleuze'jańskiej wariantu "fałd", będę w niniejszym artykule przełamywał tę tradycję, operując raczej pojęciem "fałdy", której „tekstylne” (textus/texte) konotacje pozwalają na powołanie do życia całego pola metafor, takich jak „kontrafałda”, „plisa” i „plisowanie”, „pogniecenie”, „zagniecenie”, „zagięcie”.

4 G. Deleuze, Foucault, Paris 1986, s. 104; cyt. za: B. Banasiak, De interpretatione. Deleuze versus Derrida, „Nowa Krytyka. Czasopismo Filozoficzne” 2006, wydanie elektroniczne: http://www.nowakrytyka.pl/spip.php?article24 [dostęp 30.09.2015].

5 Por. J. Łotman, Kultura i eksplozja, przeł. i wstęp B. Żyłko, Warszawa 1999. 
i „przestrzeni” Yi-Fu Tuana ${ }^{6}$ - wraz z gradientem wysycenia symbolicznego zmienia się położenie określonego obszaru pomiędzy biegunami "centrum" alias „miejsca” (po Heideggerowsku „zamieszkanego"7) i „peryferii” czy też Yi-Fu Tuanowskiej „przestrzeni”. W zasadzie „przestrzeń” jest tu już synonimem tego, co wedle Łotmana leży poza granicami semiozy, staje się dominium braku znaczeń - nie tyle może chaosu, ile "niezamieszkania”, więc w sensie fenomenologicznym prawie nieistnienia. Spektrum możliwości ma tu oczywiście charakter ciągły, a charakterystyka obszarów jest - rzecz jasna - i historycznie zmienna, i uzależniona od określonej wspólnoty interpretacyjnej.

Model "fałda-kontrafałda” w zasadzie odpowiada powyższemu; zasadniczą różnicą, jaką wnosi do tego spojrzenia, jest uzależnienie gęstości znaczeń przypisanych określonemu obszarowi nie od jakichś walorów „eidetycznych" czy aktywności sensotwórczej podmiotu (jak zakłada podejście fenomenologiczne) lub relacyjnego położenia w obrębie szerszej struktury semiotycznej (jak w perspektywie strukturalistycznej), lecz od nieco przypadkowych i dynamicznie się zmieniających nagromadzeń kontekstów kulturowych umożliwiających przejścia obszaru od statusu znaczącego (fałdy, centrum, miejsca, znaku na geopoetycznej mapie) do stanu nieznaczącego (kontrafałdy, peryferii, przestrzeni, białej plamy na mapie imagologicznej) $\mathrm{i}$, , $\mathrm{w}$ kierunku” przeciwnym.

5. „Pofałdowany” („plisowany”, „pognieciony”) charakter mapy geopoetycznej więcej zawdzięcza literaturze i tekstom kultury niż kartografii w tradycyjnym rozumieniu. Sejny czy Człuchów znajdziemy na odpowiednich arkuszach mapy geodezyjnej kraju (Mapy zasadniczej alias Podstawowej Mapy $\left.\mathrm{Kraju}^{8}\right)$ i jej pochodnych, ale na mapie geopoetycznej łatwiej dostrzec niewiele się różniący rozmiarami Drohobycz, który swoje istnienie w tej mierze zawdzięcza pojedynczemu gestowi artystycznemu.

\footnotetext{
6 Por. Y.-F. Tuan, Przestrzeń i miejsce, przeł. A. Morawińska, Warszawa 1987.

7 Por. np. H. Buczyńska-Garewicz, Miejsca, strony, okolice. Przyczynki do fenomenologii przestrzeni, Kraków 2006.

8 Por. Ustawa z dnia 17 maja 1989 r. Prawo geodezyjne i kartograficzne [Dz. U. 1989 nr 30 poz. 163] oraz późniejsze zmiany - przede wszystkim: Ustawa z dnia 4 marca 2010 r. o infrastrukturze informacji przestrzennej [Dz. U. $2010 \mathrm{nr} 76$ poz. 489] oraz Rozporządzenie Ministra Administracji i Cyfryzacji z dnia 12 lutego 2013 r. w sprawie bazy danych geodezyjnej ewidencji sieci uzbrojenia terenu, bazy danych obiektów topograficznych oraz mapy zasadniczej [Dz. U. 2013 poz. 383]. Termin ",arkusz” jest już właściwie nieadekwatny w odniesieniu do mapy zasadniczej - od momentu wejścia w życie wymienionego wyżej rozporządzenia z 2013 r. Podstawowa Mapa Kraju nie jest odwzorowaniem graficznym, lecz numeryczną bazą danych.
} 
6. Zjawisko „plisowania” mapy imagologicznej wymaga też krótkiego ekskursu dotyczącego historii, jako że wyobrażenie geopoetyczne zdaje się być analogonem historycznego mitu, tyle że realizującym się w płaszczyźnie kulturowego zagospodarowywania przestrzeni, nie czasu/dziejów. „Plisy” są bowiem raczej dziełem historii przeżywanej (społecznych mitów przeszłości) niż historii w rozumieniu naukowym (dyskursów ustanawiających "obiektywny" stan faktyczny). Powstanie sejneńskie z sierpnia 1919 r. jest faktem podręcznikowym, ale prawie nieznanym poza regionem. Zamek komturii człuchowskiej był terytorialnie największą, drugą co do ważności po Malborku, twierdzą krzyżacką, siedzibą Ulricha von Jungingen i Konrada von Wallenrode, potem siedzibą starostów Rzeczypospolitej - Wejherów, Sanguszków, Radziwiłłów. Nie są to jednak fakty znane szerokim gremiom nie-tutejszych bądź nie-fachowców.

W Borysławiu na przełomie stuleci XIX i XX istniało około tysiąca przedsiębiorstw naftowych zatrudniających około dziesięciu tysięcy ludzi. Szybów zagłębie liczyło kilkanaście tysięcy, przed I wojną światową wydobywano tu więcej ropy niż w Iranie, a Borysław był też ważnym ośrodkiem ruchu socjalistycznego (PPSD). Na wyobrażonej mapie „Kresów” czy „Szczęśliwej Galicji” figuruje jednak raczej sklep bławatny Jakuba w północno-zachodniej pierzei drohobyckiego rynku...

7. Mapa literacka to rzadko ekfraza mapy $\mathrm{w}$ rozumieniu akademickiej kartografii (są oczywiście wyjątki - np. Słowacka dwusetka Stasiuka ${ }^{9}$ ). Częściej jest to jakiś moduł tekstu poświęcony opisowi przestrzeni, przy czym oddzieliłbym tutaj deskrypcję sensu stricto związaną z reprodukowaniem/reprezentowaniem/kreowaniem zmysłowego wymiaru przestrzeni (powiedzmy „pejzażu”) od jej obrazów uogólnionych czy syntetycznych - od ideacji (dla tych właśnie rezerwując określenie „mapa” ${ }^{10}$ ).

Ponieważ mapy tego rodzaju z oczywistych względów nie mogą operować środkami odwzorowań graficznych, pisarze sięgają po metaforykę związaną z uruchamianiem różnych kodów/rejestrów kulturowych (kartografii,

\footnotetext{
9 Por. A Stasiuk, Słowacka dwusetka, w: tegoż, Jadąc do Babadag, Wołowiec 2004.

10 Jeżeli w kategoriach tradycyjnej poetyki strukturalistycznej przestrzeń świata przedstawionego jest jednym z wyższych układów znaczeniowych utworu - „pejzaż” i „mapa” byłyby może dwiema komplementarnymi strategiami uformowania tego wymiaru przestrzeni przedstawionej, który Janusz Sławiński nazywa „scenerią" (por. J. Sławiński, Przestrzeń w literaturze: elementarne rozróżnienia i wstępne oczywistości, w: Przestrzeń i literatura, red. M. Głowiński i A. Okopień-Sławińska, Wrocław 1978). Jeżeli „pejzaż” rozumieć jako deskryptywny, językowy, ekwiwalent „tego, co widać” (resp. ,jest zmysłowo doświadczalne”), „mapa” odpowiadałaby schematowi przestrzennego rozmieszczenia opisywanych fenomenów w kreowanym polu percepcji (fokalizacji). „Mapa”, w równym stopniu jak „pejzaż” jest przy tym otwarta na interpretacyjne dopełnienie w postaci „sensów naddanych” (por. J. Sławiński, tamże).
} 
fotografii, malarstwa, mitu, religii, astrologii lub kodu uprzedzeń etnicznych). To ich wykorzystanie w przypadku „map” literackich czyni je jawnie otwartymi na interpretację (w odróżnieniu od map "prawdziwych”, które ufundowane są na iluzji prawdziwości i obiektywizmu). To także bogactwo kulturowych kodów odpowiedzialne jest $\mathrm{w}$ znacznej mierze za system fałd i kontrafałd, „plisowanie” czy „zagniecenia” i „zagięcia” naszych map geopoetycznych.

Garść przykładów: Stasiuk w Jadąc do Babadag wykorzystuje symbolikę itinerarium i rozkładu jazdy ${ }^{11}, \mathrm{w}$ eseju Tylko ten lęk... - figurę rozczłonkowania człowieka makrokosmicznego ${ }^{12}$; w Parodii jako sposobie przetrwania kontynentu na stereotypowe opozycje Europy Środkowej i Bałkanów względem Europy „prawdziwej” narzuca siatkę pojęć estetycznych (naśladownictwa, parodii, kiczu, gry reprodukcji z pierwowzorem) ${ }^{13}$. Kuśniewicz w powieści $W$ drodze do Koryntu, kreśląc scenerię zdarzeń, korzysta z repertuaru imaginarium astrologicznego nieco podobnie, jak w Strefach ${ }^{14}$, Konwicki w Bohini formuje przestrzeń, nasycając ją na równi elementami mitu greckiego i romantyczno-powstańczego ${ }^{15}$, a Chwin z Huellem - posługując się asorty-

11 Służą (między innymi) temu na przykład ostentacyjnie długie enumeracje toponomastyczne, por. także w: A. Stasiuk, Mapa, w: tegoż, Fado, Wołowiec 2006, s. 36-37 i w wielu innych miejscach jego "próz podróżnych".

12 Por. np. następujący cytat: „Tak, to ten lęk, te poszukiwania, ślady, historie, które mają przesłonić nieosiągalną linię widnokręgu. Znowu jest noc [...]. Dusza rozpuszcza się w przestrzeni jak kropla $\mathrm{w}$ otchłani morza, a ja jestem zbyt tchórzliwy, żeby $\mathrm{w}$ to uwierzyć, zbyt stary, by pogodzić się ze stratą, i wierzę, że tylko poprzez widzialne można zaznać ukojenia, że tylko $\mathrm{w}$ ciele świata moje ciało odnajdzie schronienie. Chciałbym być pochowany $\mathrm{w}$ tych wszystkich miejscach, gdzie byłem i jeszcze będę. Głowa wśród zielonych wzgórz Zemplén, serce gdzieś w Siedmiogrodzie, prawa dłoń w Czarnohorze, lewa w Białej Spiskiej, wzrok w Bukowinie, węch w Răşinari, myśli może gdzieś tutaj..." [A. Stasiuk, Tylko ten lęk..., w: tegoż, Jadac do Babadag, s. 7].

13 Por. A. Stasiuk, Parodia jako sposób przetrwania kontynentu, w: tegoż, Fado.

14 Por. np. następujący cytat: „Jeżeli zawodne, pozszywane ze strzępów były moje strony po mieczu - okolice trójkąta Łąk - to miasto w zodiakalnym znaku kądzieli [podkr. - M.D.] było również wątpliwe i hybrydyczne" [A. Kuśniewicz, W drodze do Koryntu, Łódź 1994, s. 28]; w Strefach odpowiednikami znaków zodiaku, które stają się „symbolami” czy "znakami algebraiczno-astrologicznymi” są świetlne reklamy „Milka, Velma, Bittra i Kakao”, podporządkowując sobie w pamięciowo-imaginacyjnym dyskursie narratora losy, epoki życia, przestrzenie związane z bohaterami powieści - por. A. Kuśniewicz, Strefy, Kraków 1979, s. 16 i nast.

15 Por. np. następujące cytaty: „Moja babka Helena idzie przez ten nieduży kraj podobny do starożytnej Grecji. Każde miasteczko, każdy zaścianek, każde rozstaje dróg to historia ludzkości. Wszyscy tu się znają wzajem, wszyscy od siebie pochodzą i wszyscy też tworzą nową historię, nową kosmogonię, którą potem rozniosą pielgrzymi i wygnańcy po całym świecie"; "to niezapomniane powstanie wisiało w powietrzu nad Wilią, wyło po nocach na rojstach, dusiło zimą w ciemnych alkierzach dworów zasypanych śniegiem po kominy" [T. Konwicki, Bohiń, Warszawa 1987, s. odpowiednio 86 i 19]. 
mentem poetyk upiorności i melancholii ${ }^{16}$. Eustachy Rylski spatium swoich utworów bardzo wyraźnie poddaje władzy stereotypów przestrzenno-kulturowych: w Człowieku w cieniu, jakby na życzenie Jurija Łotmana, opozycja nadwołżańskiego stepu i Warszawy generuje różnice $\mathrm{w}$ charakterystyce związanych z nimi postaci („bohaterów stepu” versus „bohaterów drogi” ${ }^{17}$ ); w Warunku różnica przestrzenna Litwa - Wołyń odwzorowuje się w antytetycznie (i stereotypowo) ukształtowanych pejzażach, klimacie, mentalności i kulturowym uposażeniu, wreszcie - nawet $\mathrm{w}$ wyglądzie protagonistów; bardzo podobnie kształtuje się przeciwstawienie spacjalne Mazowsza i Podlasia w opowiadaniu Wyspa.

7. Na podstawie powyższych przykładów łatwo stwierdzić, że temu, co nazywam tu „literacką mapą” bliżej do charakterystyki - hypotypozy przestrzeni świata przedstawionego niż do reprezentacji ściśle topograficznej. Można też zapewne postawić tezę, że to, co kulturowo (w tym szczególnym przypadku: literacko) niescharakteryzowane, nie pojawia się także $\mathrm{w}$ obszarze imaginatywnej topo- i geografii. $\mathrm{W}$ pewnym sensie kulturowo nie istnieje.

8. „Efekt przedpokoju” to metafora, którą wprowadzam dla dookreślenia sytuacji pewnych (czasem niemałych, na ogół zawsze niebanalnych) terytoriów, które w wyobraźni powszechnej ukryte są pod "zagięciami” czy w "kontrafałdach" imaginowanej mapy. Literatura realistyczna obfituje w opisy pomieszczeń mieszkalnych (np. mieszczańskich salonów), na ogół rezygnując przy tym z deskrypcji przedpokojów, których istnienie jednak presuponuje. „Przedpokój” istnieje, istnieje jednak na sposób pozbawiony reprezentacji. Taki sam jest w kulturze polskiej na przykład los Suwałk (które dały nam Konopnicką, nie dały jednak własnego wyrazistego obrazu), albo Kociewia (które zanika pomiędzy silnymi sąsiednimi dyskursami „Polski polskiej” i „Polski kaszubskiej”). „Przedpokój” w tym przypadku to inne określenie kontrafałdy wyobraźni geopoetycznej.

9. Oto literackie exemplum "uprzedpokojowienia”. Mickiewiczowska Śmierć pułkownika to nie tylko przykład kreacji mitu historycznego, to zarazem przypadek montażu historii (przy okazji - Józef Bachórz w ogóle kwestionuje udział Emilii Plater w działaniach zbrojnych powstania $\left.{ }^{18}\right)$ :

\footnotetext{
16 Por. np. S. Chwin, Złoty pelikan, Gdańsk 2003 (epizod zasypanego schronu); P. Huelle, Stót, w: tegoż, Opowiadania na czas przeprowadzki, Londyn 1991; P. Huelle, Ostatnia Wieczerza, Kraków 2007 (epizod junkra-upiora); P. Huelle, Ukiel, w: tegoż, Opowieści chłodnego morza, Kraków 2008.

17 Por. J. Łotman, Zagadnienia przestrzeni artystycznej w prozie Gogola, przeł. J. Faryno, w: Semiotyka kultury, wyb. i oprac. E. Janus, M.R. Mayenowa, Warszawa 1975.

18 Por. J. Bachórz, Jak pachnie na Litwie Mickiewicza i inne studia o romantyzmie, Gdańsk 2003.
} 
W głuchej puszczy, przed chatką leśnika,

Rota strzelców stanęła zielona;

A u wrót stoi straż Pułkownika,

Tam w izdebce Pułkownik ich kona.

Z wiosek zbiegły się tłumy wieśniacze,

Wódz to był wielkiej mocy i sławy,

Kiedy po nim lud prosty tak płacze

I o zdrowie tak pyta ciekawy. [podkr. - M.D.]

Stworzony przez wieszcza obraz poetycki charakteryzuje duża siła ekspresji, ale i niewielka wierność faktom. Emilia Broel-Plater zmarła nie w zagubionej puszczańskiej sadybie leśnika, lecz w dworze Justianów należącym do Ignacego Abłamowicza, pochowana zaś jest na cmentarzu w Kopciowie (w tegoż Abłamowicza ówczesnych dobrach). Nie wśród tłumu żołnierzy-powstańców i gromad poczciwego ludu konała, ale w stosunkowo niewielkim gronie mieszkańców dworu. Z powstańczej grupy towarzyszyły jej już wówczas dwie lub trzy zaledwie osoby, ale za to środowisko, które otoczyło ją opieką w tych ostatnich chwilach, było jej pokrewne duchowo - stanem, językiem, wyznaniem, kulturą, poglądami politycznymi. Niewiele tu więc z rozpaczliwej puszczańskiej samotności obrazu Mickiewiczowskiego.

Nie tyle jednak o manowce historycznego mitu mi tutaj chodzi, ile o - analogiczny - proces „kontrfałdowania” wyobrażeń przestrzennych. Gdzie umiera bohaterka wiersza? Poeta nie dostarcza żadnych określeń, prócz słowa "puszcza”, od czasów jagiellońskich silnie wpisanego w stereotyp pejzażowy Litwy. Emilia umiera na Litwie. Ba! Ale na której? Litwa Mickiewiczowska to Nowogródczyzna, Wileńszczyzna, czasem Kowieńszczyzna i pogranicza Żmudzi - na przykład Upita... W odbiorze "ustandaryzowanym", to jest najmocniej ustereotypizowanym, Litwa Mickiewiczowska to jednak Soplicowo, którego pierwowzorem był jakoby podnowogródzki Czombrów. Śmierć Platerówny miała zatem miejsce wszędzie i nigdzie wśród litewskich puszcz, co zresztą w kontekście wiersza nie dziwi, skoro jego moc poetycka kreować miała prawdę duchową (mit odwagi, poświęcenia i ofiary), a nie z kronikarską dokładnością rejestrować zdarzenia i miejsca.

Dla wyobraźni geopoetycznej ta skrótowość, to ledwie naszkicowane tło wiersza, ma jednak znaczenie niebagatelne. Oto powiat sejneński (ponownie?) utracił szansę zapisania się na kartach zbiorowej pamięci i nie stał się ani „punktem węzłowym” polskich mitów tożsamościowych, ani „miejscem” w znaczeniu fenomenologii topograficznej i wyobrażonej mapy Rzeczypospolitej przed- i rozbiorowej. Jednym z dalszych następstw tego „niepowodzenia w karierze literackiej" jest na przykład fakt zaniku wschodniej części Sejneńszczyzny w planie polskiej zbiorowej wyobraźni przestrzennej. Dla 
współczesnego Polaka ziemia sejneńska kończy się na wschodniej granicy, poza sferą imagologiczną pozostaje litewska Suvalkija i zachodnia Dzūkija (alias Dainava) - obszar rozciągający się mniej więcej od naszej granicy do Niemna. To przedrozbiorowe ziemie województwa trockiego (powiaty trocki, kowieński, grodzieński), porozbiorowe Prusy Nowowschodnie, pokongresowe obszary królewiackiego województwa augustowskiego i guberni suwalskiej oraz diecezji sejneńskiej. Włączone do Królestwa Polskiego, przestały być Litwą. Nie włączone ani do Polski, ani do tzw. Litwy Środkowej w międzywojniu - „wypadły” poza obieg formowanego w aurze myślenia etnocentrycznego fantazmatu utraconych „Kresów”.

Emilia Plater jest pochowana około $150 \mathrm{~km}$ od Białegostoku i grób jej uczestnicy konferencji mogliby odwiedzić choćby w dniu zakończenia ob$\operatorname{rad}^{19}$. Jednocześnie jego miejsce $\mathrm{w}$ wierszu Mickiewicza jest w pewnym sensie bardziej realne niż litewskie Užnemunè, którego polski odpowiednik Zaniemenie - nic na ogół Polakom nie mówi. Kontrafałda - przedpokój nieobecność - nic ${ }^{20}$.

10. Termin „mapa”, prócz znaczenia intuicyjnie zrozumiałego, bo związanego $\mathrm{z}$ kartografią, pojawił się w powyższych rozważaniach w dwóch odmiennych użyciach.

Pierwsze związane jest $\mathrm{z}$ fenomenem deskrypcji literackiej i dotyczy pewnego ideacyjnego obrazu określonej przestrzeni (mającej lub nie swój realny pierwowzór), utrwalonego w konkretnym artefakcie językowym, na ogół indywidualnego autorstwa, pozostającego w złożonych, ale rekonstruowalnych narzędziami filologiczno-hermeneutycznymi, relacjach intertekstualnych z uniwersum tekstów kultury i wyrażonych za ich pośrednictwem zespołach znaczeń (idei, struktur ideologicznych etc.). Badanie mapy literackiej jest więc bodaj szczególnym przypadkiem standardowych operacji analizy i interpretacji tekstu - wymaga określenia "ujętego w signifikanty" "obszaru”, czyli wyodrębnienia określonego motywu przestrzennego, wskazania kodów kulturowych (literackich i kontekstualnych) biorących udział w jego uformowaniu, ujawnienia hipotetycznej „ukrytej całości” wraz ze wskazaniem kontekstów interpretacyjnych.

Mapa geopoetyczna jest natomiast zjawiskiem dużo bardziej migotli-

19 Artykuł jest nieco jedynie rozwiniętym wariantem wystąpienia zaprezentowanego na międzynarodowej konferencji naukowej „Geograficzne przestrzenie utekstowione” zorganizowanej przez Zakład Teorii i Antropologii Literatury IFP UwB, w dniach 11-12 czerwca 2015 r.

20 Z przyjemnością, ale i niejakim wstydem odnotować można za to rozbudowane, wnikliwe i - jeśli wypada użyć tego słowa - ciepłe analizy poświęcone Zaniemeniu w książce publicysty niemieckiego - por. U. Rada, Niemen. Dzieje pewnej europejskiej rzeki, przeł. M. Sacha, Olsztyn 2012. 
wym, o trudniej uchwytnej ontologii. Jest ona fenomenem kulturowym zależnym od kontekstu historycznego i społeczno-kulturowego - innymi słowy, od wspólnoty interpretacyjnej, w obrębie której funkcjonuje. Przypomina $\mathrm{w}$ jakimś sensie gatunek literacki, nie istniejąc w jednostkowym kształcie utrwalonym w określonym medium, lecz jako ideacja, abstractum zdeponowane $\mathrm{w}$ zbiorowej wyobraźni, a ufundowane w niezliczonej ilości kulturowych „kartograficznych" artefaktów, których zbiór określić łatwiej poprzez „rodzinne podobieństwo" poszczególnych elementów, niż rekonstruując jakąś skończoną listę cech dystynktywnych.

Typologia (bo raczej nie klasyfikacja) rozmaitych map geopoetycznych jako aktywnych składników wyobraźni społeczno-kulturowej (zatem także politycznej) musi więc uwzględniać nie tylko obszar podlegający „mapowaniu" i skalę (stopień ogólności „odwzorowania”), ale także środowisko, w którym określona mapa wirtualnie funkcjonuje, dominujące media oraz praktyki utrwalenia i przekazu, kody kulturowe zaangażowane w jej formowanie, wreszcie struktury ideologiczne przez nie implikowane. Na pierwszy rzut oka projekt ten wygląda na definitywnie niewykonalny - złożone z interpretacyjnych "plis" i "kontrafałd” mapy wyobrażone przypominają wzburzony ocean tkanin w sklepie Jakuba. W końcu jednak, jak mawiali w wieku XIX kartografowie zesłani na Sejneńszczyznę - стремиться надо...

\section{Literary Maps - the Rhizome, the Fold and the "Antechamber Effect"}

\section{Summary}

The paper summarizes some remarks on the metaphor of map, as it is used within the field of geopoetics. The first of its meanings refers to representation of literary space in a work of fiction. The second is often applied to describe an imaginary vision of real geographic (political, economic etc.) space. It is therefore determined (or "created") by culture, or rather by innumerable cultural texts, which affect our common, i.e. culture-dependent imagination. In both cases "the map" should not be considered as a representation in its traditional meaning of something essentially present or given. Instead, Deleuzian metaphors of the rhizome and the fold seem more convenient here, as they highlight this unready, process- and interpretation-dependent character. The sets of metaphorical notions, such as "fold/ply", "double fold/twofold/two-ply" and "folding/creasing/ironing imaginary maps" are used in this paper to clarify the idea of "antechamber effect". In consequence, this is a phenomenon which, within the realm of literary imagination, renders some real territories with weak cultural potential nonexistent.

Keywords: geopoetics, literary space, literary maps, cultural imagination 